\title{
The FinTech phenomenon: antecedents of financial innovation perceived by the popular press
}

\author{
Liudmila Zavolokina*, Mateusz Dolata and Gerhard Schwabe
}

\author{
* Correspondence: \\ zavolokina@ifi.uzh.ch \\ Department of Informatics, \\ University of Zurich, 8050 Zurich, \\ Switzerland
}

\begin{abstract}
The financial industry has been strongly influenced by digitalization in the past few years reflected by the emergence of "FinTech," which represents the marriage of "finance" and "information technology." FinTech provides opportunities for the creation of new services and business models and poses challenges to traditional financial service providers.

Therefore, FinTech has become a subject of debate among practitioners, investors, and researchers and is highly visible in the popular media. In this study, we unveil the drivers motivating the FinTech phenomenon perceived by the English and German popular press including the subjects discussed in the context of FinTech. This study is the first one to reflect the media perspective on the FinTech phenomenon in the research. In doing so, we extend the growing knowledge on FinTech and contribute to a common understanding in the financial and digital innovation literature. These study contributes to research in the areas of information systems, finance and interdisciplinary social sciences. Moreover, it brings value to practitioners (entrepreneurs, investors, regulators, etc.), who explore the field of FinTech.
\end{abstract}

Keywords: FinTech, Innovation, Digitalization, Content analysis, Popular press

\section{Introduction}

The world of finance, particularly the banking sector, is of undoubted importance to the daily lives of people worldwide. Traditional banking has changed significantly during the last century but, today, a new epoch of financial service, called "FinTech," has emerged. This sector represents a challenging environment because it has barely been explored.

There is no doubt that traditional financial technologies have undergone a huge transformation throughout the last decade, and the new types of financial technologies - FinTech - represent a currently innovative and emerging field, which has attracted attention from the media as well as investors. According to an Accenture report (Skan et al. 2015), the number of investments in FinTech companies and start-ups has risen dramatically within one year from USD 4.05 billion in 2013 to USD 12.2 billion in 2014. The amount of investment in the industry has almost doubled to USD 22.2 billion for the year 2015 (Skan et al. 2016). These figures demonstrate that the sector is highly visible in the world of finance and, therefore, provides fertile ground for further ingenious ideas and research. Moreover, FinTech brings new opportunities for individual empowerment, for example, by allowing transparency, reducing costs, or cutting

(c) The Author(s). 2016 Open Access This article is distributed under the terms of the Creative Commons Attribution 4.0 International License (http://creativecommons.org/licenses/by/4.0/), which permits unrestricted use, distribution, and reproduction in any medium, provided you give appropriate credit to the original author(s) and the source, provide a link to the Creative Commons license, and indicate if changes were made. 
middlemen and, even more importantly, by making information accessible. FinTech also affects banks that are cautious of being disrupted and that are attempting to jump on the FinTech train while observing the thousands of start-ups offering alternatives to traditional banking services.

Although the term "FinTech" is in the limelight of public debate in the fields of business, finance, and innovation, its meaning is ambiguous for many people. This ambiguity is felt by experts in the FinTech field and the targeted external consumers who are observing this emerging field. One reason for the ambiguity could be the novelty and tremendous rapid rise of the FinTech industry. FinTech is a broad phenomenon that is evolving daily as more technology entrepreneurs enter the industry and transform it according to social needs. On the one hand, FinTech could be considered a financial service, which is intervened by innovative technologies to satisfy the requirements of tomorrow: high efficiency, cost reduction, business process improvement, rapidity, flexibility, and innovation (Dapp et al. 2014). On the other hand, FinTech also refers to companies - and, even more typically, to start-ups, which serve as enablers of these services. Currently, the term "FinTech" is ambiguous, and there is room for further discussion. We argue that elucidating on the antecedents of FinTech will aid practitioners in identifying the potential and threats associated with the phenomenon and researchers to unveil new possibilities for study on all aspects of FinTech (e.g., the supporting technologies, ecosystems, and organizational factors).

The significance of the financial industry in economic growth emphasizes the role of financial innovation, which can be considered a new entity that involves the reduction of risks and costs or the provision of a product/service/instrument that meets the needs of involved parties better than existing options (Frame and White 2014). Considering the technological breakthroughs within the scope of financial services, the current climate invites reflection on the main FinTech subjects from the perspective of key media $^{1}$ and industrial sources, which are naturally involved in specific societal discourses and frame the notion of FinTech accordingly.

While a generous amount of research addresses the field of financial services and the banking sector, only a few scholars have touched on the FinTech industry. The context of research is broad today, and unexplored new horizons constantly emerge as new FinTech companies spring up like mushrooms overnight and reinvent the industry. This disruption is the motivation for our examination of how FinTech harmonizes and engages with the real world. Because the research on FinTech in the information systems (IS) research community is in its infancy and only a few studies address the subject, we assume an explorative and qualitative approach and base our analysis on the results of a review of scientific publications, professional reports, and articles from newspapers and magazines. Media discourses on the aspects of information technologies have drawn little attention from IS researchers (Cukier et al. 2009). However, we believe that the popular media is an important observer and reflector of the public consensus and plays an influential role. Therefore, we consider it worthy of researchers' attention, and argue that this study is valuable for researchers in finance area (especially ones interested in financial innovation research) and interdisciplinary social sciences (such as media and business researchers). However, such an analysis remains a reflection of the reflection of the actual reality. The majority of the sources used in this study were obtained through research and newspaper databases from North America and the English and German-speaking countries in Europe. 
Inspired by the explosion of media attention on FinTech, we present an overview of locations, people, their motives and intentions, organizations, and relationships, as well as central historical events that shape and underlie the phenomenon. Moreover, we identify central discourses around FinTech and its role in the current environment. Therefore, we set the following research question:

What factors influence the perception of FinTech through the lens of the media, and how has this influence been changing over time?

To address our research question and support our argument, we subdivide the research question and focus on two aspects to guide the reader through the analysis. These are the following:

(1) What are the primary factors that influence FinTech over time?

(2) What FinTech-related subjects are discussed in the press?

The contribution of this study is threefold. First, it contributes to the literature on financial and digital innovation by positioning FinTech within that context and identifying and analyzing the drivers motivating FinTech as perceived by the popular media. We analyze a range of sources and, based on this analysis, we reflect on the development of FinTech through the eyes of the press. This aids scholars who are attempting to define the starting point and a basis for their research on FinTech. Second, this study employs a methodological approach, which can be used to explore the new field in IS and reveal a consensus on the phenomenon obtained from social actors (the press in the case of this study). Third, the study also has practical implications. As a reflection of a socially constructed phenomenon, this study might appeal to entrepreneurs and investors who already focus their activities on innovative financial services or who are considering FinTech as a possible strategic direction.

The main findings of this study unveils the drivers motivating FinTech over time. We argue that FinTech is rather an entrepreneurial phenomenon, which is not triggered by exclusively one and only driver of financial innovation, but rather is influenced by the combination of economic, technological and regulatory factors. We conclude that an emergence of FinTech in the media should attract attention of researchers and encourage to explore the area and contribute to its understanding from different perspectives.

The remainder of the paper is organized as follows. In Related work, we refer to the available scientific literature, which provides the basis for discussion. We provide a glimpse into the existing FinTech literature and build on our theoretical background identifying the meaning of financial and digital innovation and the main drivers of financial innovation. Subsequently, we outline the research Methodology of this study under the respective section. Under Results, we provide an overview of the collected data, both quantitative and qualitative, and the observations. Our results include two components: the main actors involved in the development of the phenomenon (namely organizations, persons, and locations) and the subjects that arose in the context of FinTech during the studied period. We then summarize our analysis and research findings under Discussion. Here, we discuss how the perception of FinTech fits into the media discourses observed in the studied sources. The drivers of FinTech are the focus, and 
we discuss how they motivate the phenomenon and create an ecosystem for FinTech innovations. This leads us to Conclusions and limitations, which also presents the scope for future research.

\section{Related work}

Although the phenomenon of FinTech is still gaining popularity and interest among IS researchers, there have been attempts to elucidate on the new industry. Zavolokina et al. (2016) propose the conceptual framework of an understanding of FinTech perceived by the popular press. This conceptual framework represents the reflection of public opinion on the transformation occurring in the financial sector and, therefore, by its nature can be an evolving entity. The conceptual framework proposes that FinTech has three dimensions - input, mechanisms, and output and acts as a transformation machine. This machine uses technology as an input combined with organization and investment flow. The transformation includes activities such as "create/change/improve" that are applied to information technology to finance, disrupt, and create competition. As the output of such transformation, new services, products, business models, or processes are created. In our study, we examine the antecedents of such transformation and discuss how they fit and shape the perception of FinTech within the presented conceptual framework.

FinTech is closely related and linked to financial innovation. Therefore, we address the literature on financial innovation complementing it with the basic and wellestablished understanding of digital innovation. Frame and White (2014) provide an overview of how financial innovation has changed within three categories - new products and services, new production processes, and new organizational forms. Financial innovation can be considered "the act of creating and popularizing new financial instruments new financial technologies, institutions, and markets" (Lerner and Tufano 2011). Scholars have approached financial innovations from different perspectives, for example, historical (Miller 1986), functional (Merton 1995), legal, and organizational viewpoints. Moreover, according to Cuesta et al. (2015), there is no doubt that FinTech parallels global digitalization and, therefore, we provide a definition of digital innovation, which we refer to in this research. Digital innovation is defined by Fichman et al. (2014) as a "product, process, or business model that is perceived as new, requires some significant changes on the part of adopters, and is embodied in or enabled by IT." We provide insights into the antecedents of FinTech from the perspective of the popular media. This helps to identify the links between the overall innovation discourse and the FinTech phenomenon.

In our study, we address both parts of the research question in identifying the drivers that underlie and motivate the FinTech phenomenon. Therefore, the literature that highlights the main forces that advance financial innovation is the focus. These drivers are not mutually exclusive and naturally overlap each other. Studies agree that tax changes and changes in governmental regulations are not the only influences on the creation of new opportunities and the potential for "successful" innovations (Frame and White 2004; Miller 1986; Tufano 2003). Financial innovations that are influenced by taxes or regulations can be seen as both a socially positive or negative phenomenon (Frame and White 2004). For example, one prominent case which demonstrated how regulation may foster innovation is related to IBM, which controlled over the $70 \%$ of 
the computer market and was considered to be a monopoly. The United States Department of Justice forced the company to separate its hardware and software business, which stimulated competition and innovation in the industry, led to lower prices ("Regulation of IBM 1996). Another driver of financial innovation suggested by the literature is underlying technologies (e.g. telecommunications or data processing) that enable more accurate risk management (Frame and White 2004; Tufano 2003). Additionally, Frame and White (2004) consider that instable macroeconomic conditions might foster financial innovations because the conditions create uncertainty and risk such as global economic crises. Moreover, having summarized the literature on financial innovation, Tufano (2003) derives other factors that stimulate financial innovation. These include market incompleteness or the unfulfilled needs of market players; agency issues, and information asymmetries, referring to conflicts of interests between involved parties; and transaction, search, or marketing costs such as, meaning innovations that aim to reduce costs. These are the main factors influencing and stimulating financial innovations suggested by the literature. The factors are not listed and discussed in order of priority, weight, or the impact they have on innovations. Therefore, we do not assess them from this perspective. We note that all of them refer to dynamic and changing notions and not stable constructs, which corresponds to the approach of our study on FinTech as it has changed over time.

\section{Methodology}

To identify and discuss the antecedents and the drivers of the FinTech phenomenon, we analyze the media discourse on the socially constructed understanding of the phenomenon, the interrelationships between influencing factors and technological change which are treated as unavoidable (Cukier et al. 2009). Discourse analysis of novel concepts faces specific methodological challenges: the starting point for the analysis is often an underspecified buzzword rather than a well-designed concept. Consequently, the method used in this study enables an exploratory and open-ended approach to the data. Because newspapers form the base of our inquiry, the applied method acknowledges the not-neutral and subjective features of the considered texts. There is a notable variety of methods employed in constructive approaches to datasets ranging from content analysis to a family of discourse analysis methods including critical or interpretative discourse analyses and radical humanism (Cukier et al. 2004; Wooffitt 2005). These paradigms differ in their conceptualization of the discourse. Because of the exploratory nature of our research, and based on the need to broadly characterize the phenomenon FinTech, we adhere to the interpretative paradigm. We assume the reality and discourse to be socially constructed and focus on examining the status quo rather than affecting change (Cukier et al. 2004). We enrich the analysis by employing tools typical for content analysis such as the identification of central entities and dominating topics in the texts. This allows for a better illustration of the identified trends and discourses.

\section{Data collection}

To provide a broad and well-grounded analysis on FinTech discourses, we identified a set of influential opinions from newspapers from English and German-speaking regions of Europe and North America. Overall, we selected 46 different newspapers based on 
the 2015 Newspaper Web Ranking ("Newspapers 2015) that use web metrics extracted from the following services: Google Page Rank, Alexa Traffic Rank, and Majestic SEO Referring Domain. This ranking shows the popularity of certain newspapers and their webpages - it represents the impact of a newspaper in both the real and virtual worlds, which is an important criterion given the strong relationship between our phenomena of interest and modern ICT. Our selection of newspapers and magazines included 11 from Germany, nine from the United States, five from the UK, three from Switzerland, one from Austria, two from Canada, and 15 that address international audiences. To identify relevant articles, we conducted a keyword search in the Factiva database ("Factiva.com 2016). We used the keyword "fintech" and applied the following constraints: (a) the date December 31, 2015 (without any lower time boundary), (b) English or German language, and (c) corresponding to the selected sources.

\section{Data analysis}

The above procedure yielded 829 articles. A subset of approximately $6 \%$ of the articles was randomly chosen to provide the first indicators for the possible directions of qualitative coding to be applied to the whole set of articles. We considered this step necessary to establish a common understanding of the nature and characteristics of our data among the involved researchers. This step also enabled the establishment of a seed coding schema and the overall coding routine. To identify and characterize discourses related to FinTech, a single researcher, under the supervision of two other researchers, employed inductive coding. Attention was paid to the content as well as to variations in attitudes towards FinTech. Of specific interest are passages including the definition or interpretation of the term "FinTech." The number of times an argument or a term appears in the text does not provide any additional meaning. However, we indicate the subjects that dominate the discourse. The coding scheme used for the whole corpus is illustrated in Figure 6 in the Appendix.

To identify the main players shaping FinTech during the studied period and to develop further understanding of the central dimensions and trends, we employed a technique borrowed from natural language processing or entities recognition. With the help of the Stanford Named Entity Recognizer (NER) using predefined models for English (Finkel et al. 2005), we extracted entities falling into one of the following categories: PERSON, LOCATION, and ORGANIZATION. The results underwent a manual consistency check and cleaning across the dataset: (1) occurrence data for different entity names that refer clearly to one entity were merged (e.g., Google Corporation and Google), (2) all locations were clustered according to region, (3) named entities occurring in less than four articles were ignored in further analysis. These changes guaranteed easier identification of the dominating trends.

\section{Results}

\section{Who, where, and what}

In this subsection, we address the first part of the research question and identify the primary actors stimulating the phenomenon over time.

Overall, 487 articles in English were processed by NER. The articles date from October 1986 to December 2015. This procedure showed that 30 persons, 88 locations, and 118 
organizations were mentioned throughout the articles that appeared more than four times. Then, these entities were subdivided into subclasses as shown in Tables 1, 2 and 3. The category ORGANIZATION was subdivided into 12 subclasses, and PERSON was subdivided into three subclasses. Table 3 shows the number of entities of the category LOCATION in relation to the geographic region to which they belong. The numbers in Tables 1, 2 and 3 show how many entities belong to each of the subclasses. For example, subclass "Financial institution" includes 50 different organizations. Each entity was categorized as belonging to one class only.

Figure 1 shows that the number of published articles per year during the studied period was inconsistent. The number hardly changed between the years 1986 and 2001 (with peaks in 1987 and 2001 - 10 publications each year) but, notably, the number increased between the years 2010 (three publications per year) and 2015 (285 publications per year). Considering the most notable recent crises in the world economy and their strong influence on the market, we roughly divided the years between 1986 and 2015 into three periods - from 1986 to 2001, from 2002 to 2009, and from 2010 to 2015. The first marker (1) is set to the year 2001 at the end of the bursting of the dotcom bubble. The second marker (2) is set to the year 2009, which is considered the end of the global financial crisis. There were no articles published from 1991 to 1994 and from 1996 to 2009, as can be seen in Fig. 2.

Figures 2, 3 and 4 illustrate the percentage of mentioned subclasses of entities. Because of the insignificant number of articles (varying from zero to 10 articles per year) during the period from 1986 to 2001 and from 2002 to 2009, the data were aggregated for these periods, whereas the data for the period from 2010 to 2015 are presented for each year. Gaps in the graphs imply that there were no articles published or no entity of the subclass was mentioned. Three periods, which are further discussed, are marked in green in Figs. 1, 2, 3 and 4. In this section, we describe the general trends and present top "players" that are visible in the media sources for each of the periods.

\section{From 1986 to 2001}

\section{Organizations}

As can be observed from Fig. 2, IT companies strongly prevail at the beginning (1987 to 1989) and end (2000 to 2001) of the period; however, financial institutions are

Table 1 Subclasses of the category "ORGANIZATION"

\begin{tabular}{lll}
\hline & Financial institution & 50 \\
IT company & 29 \\
Start-up & 18 \\
Accelerator & 5 \\
Consulting company & 5 \\
Organization & Governmental organization & 3 \\
& Educational institution & 2 \\
Membership organization & 2 \\
Retailer & 1 \\
Regulator & 1 \\
Telecommunication company & 1 \\
Property company & 1 \\
\hline
\end{tabular}


Table 2 Subclasses of the category "PERSON"

\begin{tabular}{|c|c|c|}
\hline & Head of a company & 17 \\
\hline \multirow[t]{2}{*}{ Person } & Investor & 7 \\
\hline & Politician & 6 \\
\hline
\end{tabular}

present in 1990 and 1998 and retailers in 1988, 1999, and 2001. Fintech Limited and Xerox are active players at the beginning of the period (1987 to 1989), whereas in the middle of the period (1990, 1998), Bank of America, Morgan Stanley, the Federal Reserve (Fed), and Fidelity Investments are highlighted by the press. The end of the period (1999 to 2001) features Xerox, Coca-Cola, and Amazon at the forefront.

Persons

Few articles mention individuals in this period (Fig. 3). According to the data, the only person mentioned is David Martinez, head of FinTech Advisory, which appears in the next period as one of the most-mentioned organizations.

\section{Locations}

Europe and North America are constantly present throughout the period, with peaks in 1986 for Europe and 1997 for North America when these regions alone dominated (Fig. 4). During this period, Europe is represented mainly by the UK, while North America is mostly represented by the US and Canada. Between the years 1987 and 1989, Africa was a focus of the media particularly, South Africa.

From 2002 to 2009

\section{Organizations}

Financial institutions were the most visible type of organizations during this period peaking from 2004 to 2005 and then again in 2007 to 2008 (Fig. 2). The top-mentioned entities of this period do not show individual predominance; however, five of 10 entities are banks (Bank of America, BNP Paribas, Citigroup, Lehman Brothers, UBS), which indicates the strong presence of the banking industry during this period.

\section{Persons}

During this period, publications for three years (2003, 2004, and 2006) out of seven years mention individuals. The individuals belong to the class "Head of a company" (Fig. 3), and the two individuals mentioned are David Martinez and Donald Trump. Donald Trump belongs to the subclass "Head of a company" because of his activities at

Table 3 Mentioned locations categorized by region

\begin{tabular}{lll}
\hline & Europe & 39 \\
North America & 24 \\
Region & South America & 9 \\
& Asia & 7 \\
& Middle East & 4 \\
& Africa & 3 \\
& Australia & 2 \\
\hline
\end{tabular}




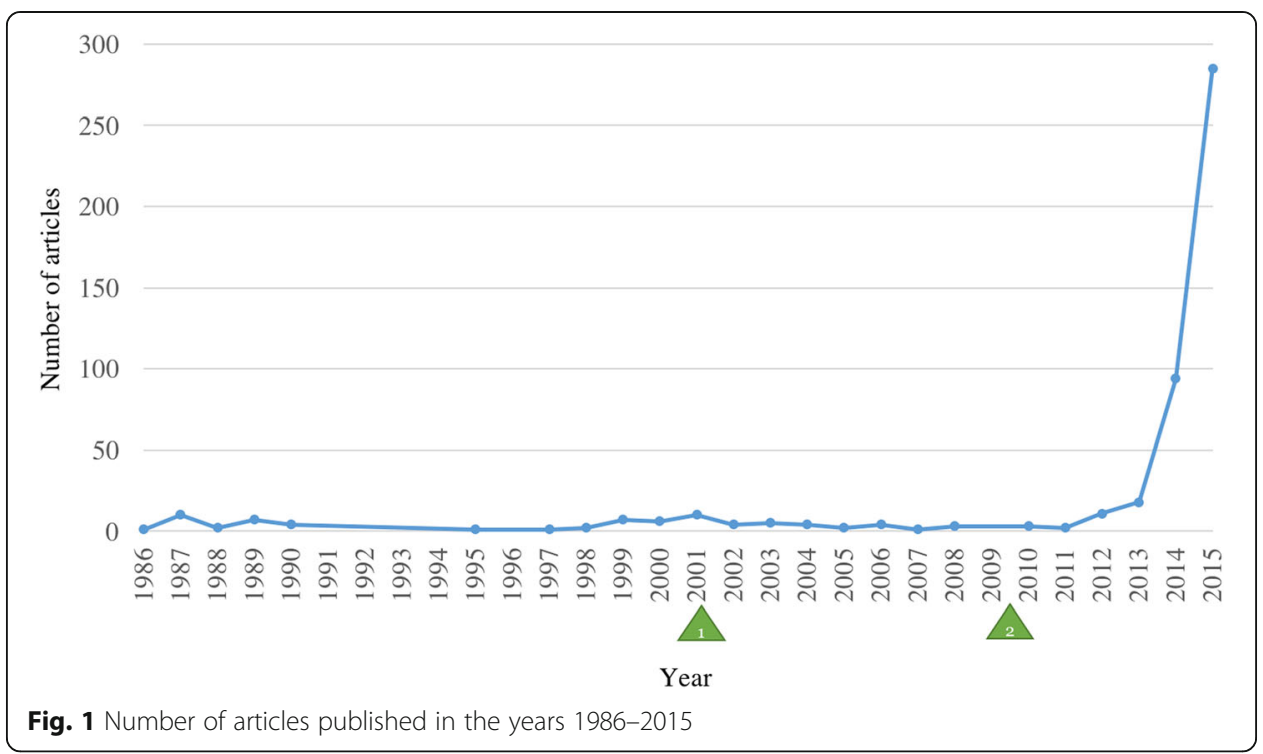

the time of the publications and during the period overall. In our classification, we attach one entity to one subclass only and, therefore, omit some additional roles of individuals.

\section{Locations}

Although Europe and North America are the leading markets, we observe South America (represented by Latin America, Monterrey, and Mexico) as an emerging FinTech region for the years 2003 and 2007. Moreover, Asia (represented by Japan) is a subject of increasing interest and was covered by the press in 2004 (9\%), 2007 (20\%), and 2008 (60\%) (Fig. 4).

\section{From 2010 to 2015}

\section{Organizations}

We can observe an increase in the range of players (organizations) involved: from three subclasses (Accelerator, Consulting company, Financial institution) in 2010 to 12 subclasses (all subclasses mentioned in Fig. 2) in 2015. From 2010 to 2015, we can note a

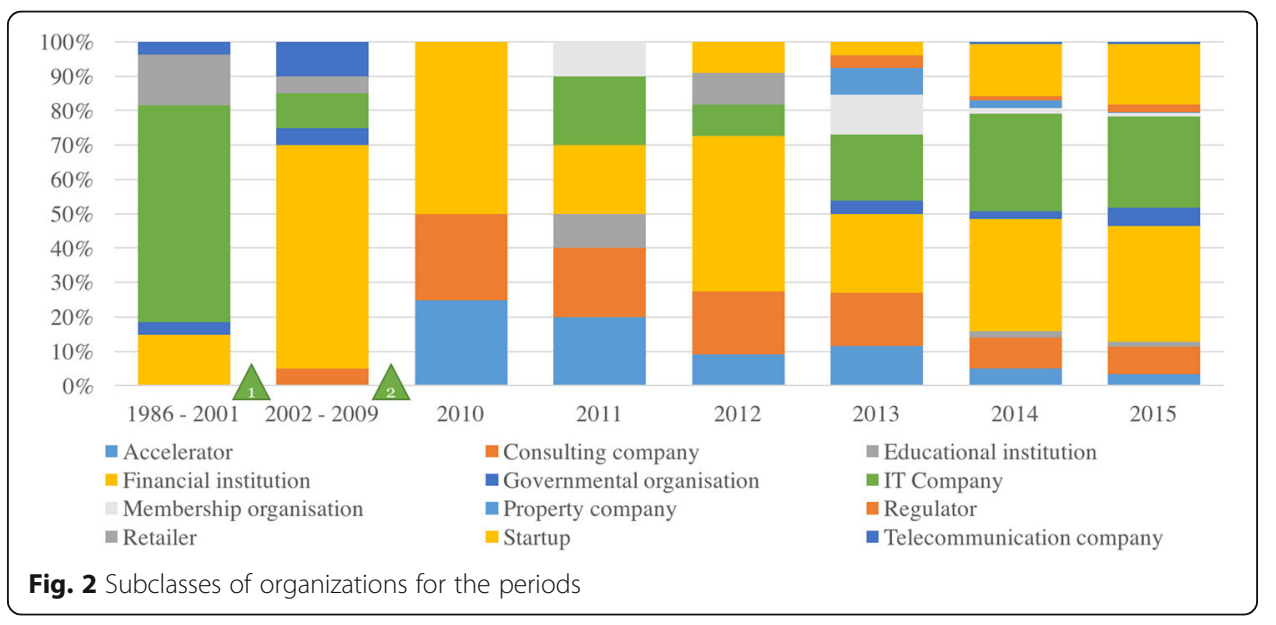




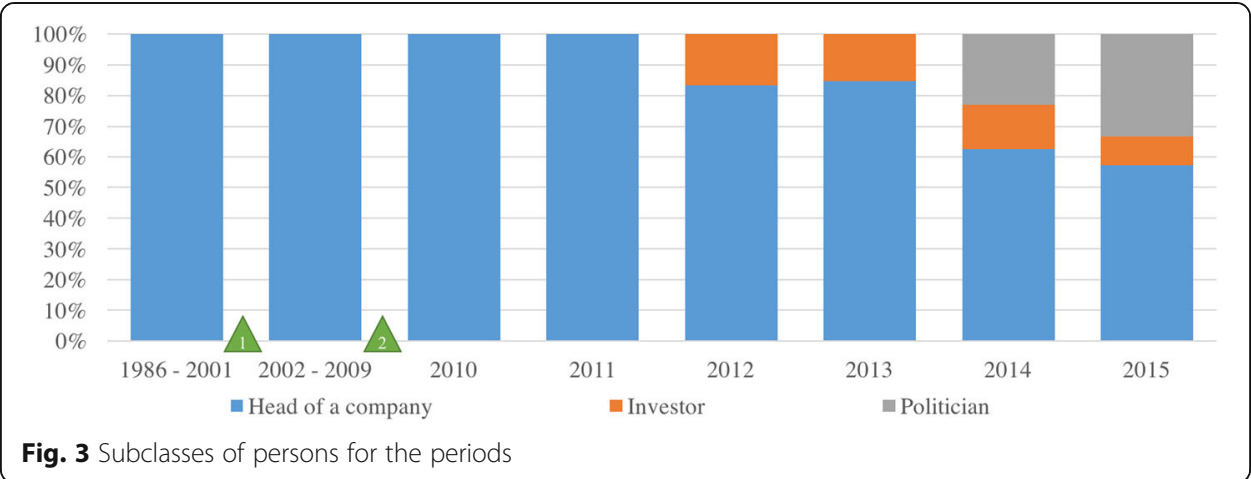

decrease in the percentage of accelerators and consulting companies, and an increase for financial institutions, start-ups and IT companies. The most highlighted organizations within the period include four IT companies (Amazon, Apple, Google, PayPal,) and four financial institutions (Barclays, Goldman Sachs, JPMorgan Chase, Morgan Stanley), one consulting company (Accenture), and one start-up (TransferWise).

\section{Persons}

Figure 3 shows a shift from the press discourse at the top management level (represented by the subclass Head of a company) in 2010 to a more diverse discourse where investors and politicians are more involved and interested in FinTech activities from 2012 to 2015.

\section{Locations}

More regions become involved in the FinTech arena during this period. Although North America and Europe prevail, Asia (2010 to 2011, 2013 to 2015) and South America (2012 to 2015) are visible in the publications (Fig. 4). The top locations mentioned in the articles are either in North America (with special focus on Silicon Valley and New York) or in Europe (focusing on the UK).

\section{What does the media talk about?}

This subsection of our results answers the second part of the research question and presents our findings on the subjects that emerge from the articles on FinTech and that constitute our body of knowledge. We observe (Fig. 5) that starting from 2010 (before 2010, the articles referring to FinTech mentioned companies' names), the subject of

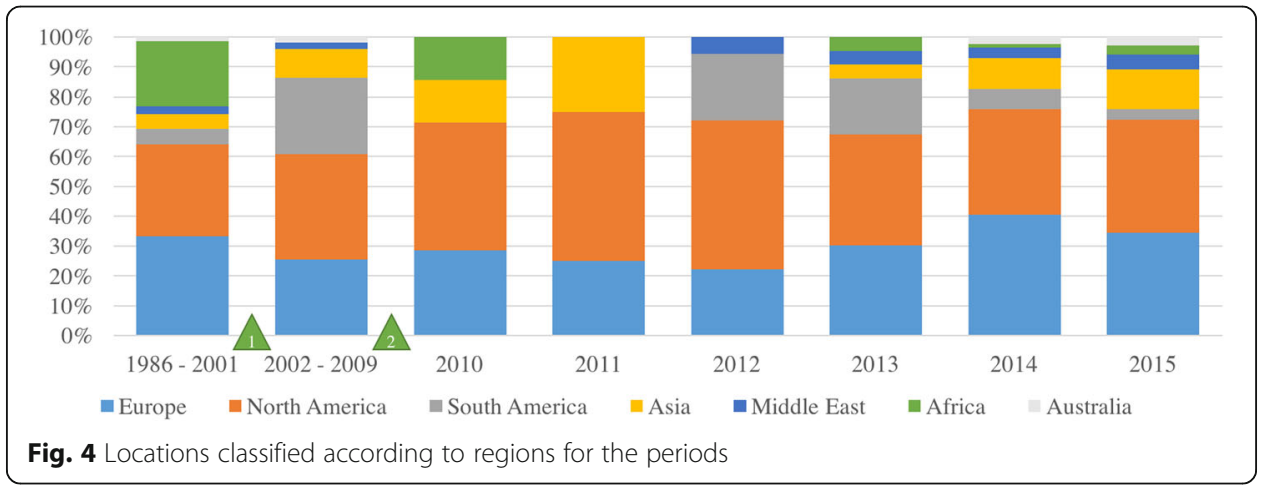




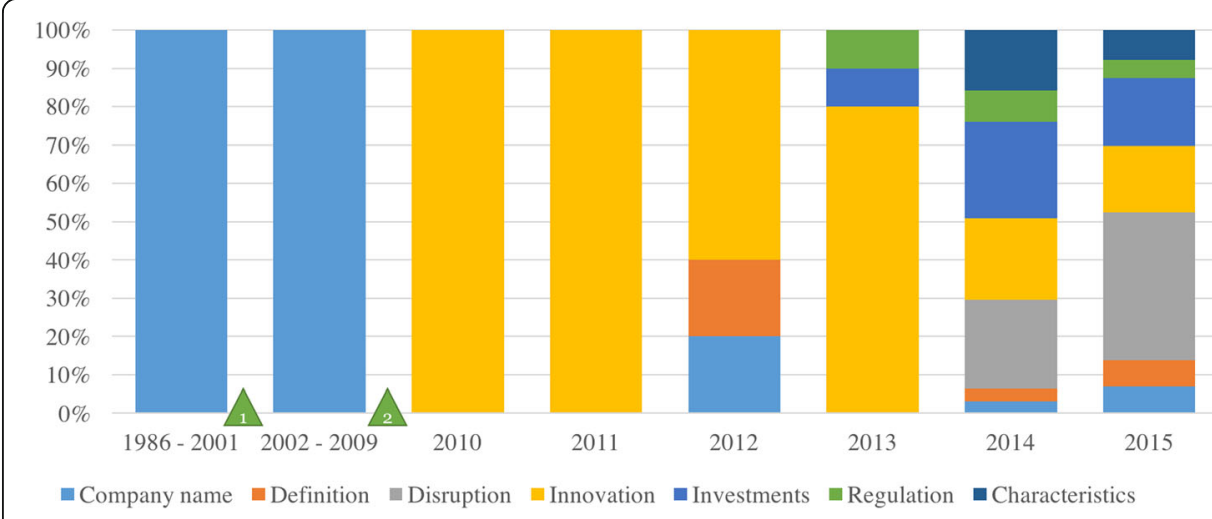

Fig. 5 Subjects of focus in the context of FinTech

innovations emerges as a general discussion, in terms of the creation of innovation labs, incubators, and accelerators, or calls for innovations. However, over time, the weight of this topic decreases. In 2012, the media began to provide a non-scientific definition of FinTech. From 2013, there is a variety of subjects discussed: the number of subjects increases from three in 2013 to six at the end of 2015. As mentioned, in the past two years, the FinTech industry has attracted massive amounts of investment, which almost tripled in two years from USD 4.05 billion in 2013 to USD 12.2 billion in 2014 (Skan et al. 2015) and reached USD 22.2 billion by the end of 2015 (Skan et al. 2016). These figures are supported by our next finding: the topic of investments gathers more attention from 2013 to 2015. However, the subject of investments refers to the money flowing in and can also be seen from a different perspective - as novel technologies for investment management solutions, for example, "automated financial planning and portfolio management tools and services." From 2014, the subject of disruption increases and is the most discussed subject in 2015. Here, articles critically look at FinTech as a "great disruptor" of banking and, moreover, discuss its disruptive character and the way it will affect traditional money management. The future opportunities of FinTech interaction with banks are discussed such as the survival of traditional players, the extent of cooperation between the traditional players and FinTech, and the winners and losers of the "game." This subject parallels the subject of regulations faced by FinTech, which appears in the press in 2013. These articles discuss the role of regulators in relation to FinTech start-ups and technologies, the likelihood that firms can adapt to regulations, whether the financial regulatory framework is too strict, and the influence of regulatory changes on the FinTech ecosystem.

In addition to contextualizing FinTech in the areas mentioned, some articles provide a general, objective account and discuss the subject extensively. Characterizing features of FinTech (such as speed of intervention, opportunities, and fears associated with FinTech) are important. Therefore, we observe that many of the articles address the implications of FinTech for the same subject but from different perspectives.

\section{Discussion}

This study addresses the following question: What factors influence the perception of FinTech through the lens of the media, and how has this influence been changing over time? To approach the research question and to provide a better understanding of the 
topic, we consider the drivers of FinTech that shape the phenomenon and, moreover, we examine the themes discussed by the media in the context of FinTech. Therefore, we subdivide the research question into two parts: (1) What are the primary factors that influence FinTech over time? (2) What FinTech-related subjects are discussed in the press? In this section, we present the findings of the study and explain the causality and interrelations between the examined phenomenon and its reflection in the popular press.

Previous studies show that FinTech, in its current state, is being highlighted by the press but is hardly present in IS research (Zavolokina et al. 2016). FinTech is a living body with a flexible and changing nature rather than a stable notion that is transparent and clearly understood by both academia and the media. To overcome the ambiguity, we contribute to the common understanding of FinTech and stimulate further research in this area.

Following studies by Frame and White (2004) and Tufano (2003), we observe changes in FinTech that are driven by certain factors. Our data show proposed impulses that trigger innovations. Reflecting back on the four dimensions and their dynamics - organizations, people, geographical locations, and the subjects discussed - we address whether the four dimensions influence and motivate the emergence and expansion of FinTech and how they fit into the theoretical knowledge on the drivers of financial innovations discussed in the related work section (and marked for further guidance through the paper).

As shown in the results on subject distribution (Fig. 5), regulations regarding FinTech are attracting increasing attention. Changes in regulations are one of the emerging subjects in articles in the last three years. Growing interest in the subject shows the importance of a clear legal framework for financial activities within which FinTech operates. Changes in such regulations may have a positive influence encouraging innovation or a negative influence, challenging market players. However, we argue that, conversely, there is an existing influence on regulation and legislation from FinTech, which makes the FinTech players adapt themselves to the current conditions of a competitive global market that poses challenges to traditional banking institutions. This explains why regulatory institutions and politicians are entering the arena of FinTech, as reflected in Figs. 2 and 4. After the 2007-2008 global financial crisis, the level of trust and interest in financial institutions dramatically decreased and spanned many different parties and markets that were supported by regulators who shape the legal ecosystem.

Although this study does not discuss specific underlying technologies, we confirm the influence of technologies on the evolvement of FinTech by the steady activity of IT companies during the period before the dot-com bubble and IT start-up explosion that occurred after the global financial crisis. Figure 2 shows that the core business of such organizations crucially requires technologies (e.g., those provided by well-known IT giant Google or the UK start-up TransferWise operating in digital payments). This is also supported by derived definitions provided by Zavolokina et al. (2016), which state a clear link between technologies as an input for transformation and FinTech.

Agency issues and information asymmetries have also significantly influenced FinTech because industry participants are acknowledged as disruptors of classical banking, financial, and insurance institutions, which are barriers to services. However, FinTech has not yet gained significant market share, a situation that may change in the near 
future, bringing serious challenges in terms of disruption. This situation is related to high transaction, search, and marketing costs, which, according to the conceptual framework, are derived in Zavolokina et al. (2016) and are one of the areas that FinTech providers look to address. In the case of FinTech, this issue is a challenge to be resolved rather than an actual driver of innovation.

The strong influence of negative economic events, which create instability and uncertainty in the market, on the development of FinTech during the study period is observed by instable macroeconomic conditions, and is one of the drivers of financial innovation. This was illustrated by the dot-com crash (green marker 1 in Figs. 2, 3 and 4) of the late 1990s to early 2000s, mostly in the US and partly in Europe, which impacted leading players in the field of IT. This explosion caused a shift from the strong participation of IT companies to the strong participation of financial institutions because of a lack of trust in failing companies. These changes are illustrated in Fig. 2; note the difference before and after 2001. This also explains the shift from a focus on the US and Europe to new "playing regions" such as Asia and South America, which serve as new growing markets. This growth, consequently, may indicate yet unfulfilled needs, thereby filling the gaps of market incompleteness. These effects were even more visible after the global financial crisis (green marker 2 in Figs. 2, 3 and 4), when more players - both organizations and regions - became actively involved and increased the variety of subjects in the context of FinTech. Figures 2 and 4 support this argument; consider the number of various branches and world regions appearing in the articles after 2009. Moreover, note that the comparatively low number of mentioned persons, as well as the lack of variety (only three categories in Table 2) indicate that FinTech is not a mainly entrepreneurial phenomenon. If this were the case, the media coverage of "war stories" between the actors in the discourse would be far more extensive (for example, the case of influential people on social media) and prominent. Here, FinTech remains a poorly understood structural change driver in the financial industry, which should be further examined.

We conclude that all the drivers discussed do not act exclusively but are a catalyst to FinTech activities. This combination of regulatory issues, technological advances, information asymmetries between market participants, economic instabilities, and market incompleteness stimulates innovation at the crossroads of finance and technology.

\section{Conclusions and limitations}

This study used an explorative and descriptive approach to address the term "FinTech." The results of this study show that FinTech is an emerging concept in the industry but is rarely mentioned about in IS research. The explosion of FinTech as a subject of media focus suggests that a collection of knowledge is highly required and should not be limited to technological aspects. Therefore, we offer the first step towards the comprehension of FinTech, unveiling its potential and providing practical applications of IS research.

This study contributes to the research in three ways. First, it contributes to the financial innovation and digital innovation literature by extending the available knowledge on the drivers of innovation and by positioning FinTech in the context of the existing research. This serves as a basis for future studies on the FinTech phenomenon. Moreover, we provide an overview of how this phenomenon has evolved and developed over 
time. In doing so, we reveal the main "building blocks" of FinTech. We highlight the importance and novelty of FinTech for scientists in various areas (finance, information systems, social studies). This article serves as a call to and inspiration for researchers. Second, this study provides a methodological approach to an analysis of the phenomenon that is missing in the research but emphasized by social entities (represented by the popular media in this study). Third, this study is of practical value to researchers, participants of the financial markets, and other interested parties who are seeking a retrospective look at the origins of FinTech or the activities in this area. Moreover, this study is the first one to bring the perspective of the media to the understanding of FinTech.

This study has several limitations that provide opportunities and new directions for future research. First, we focused only on sources of information from European countries, the US, and Canada. The researchers who performed this study could review articles written in German and English only and, therefore, these were the focus of the study. Additionally, the application of the technique of NER was only applied to the articles written in English. However, we assume that Asia does not lag in technology and development and has potential for growth offering new FinTech hubs. For example, KPMG's (2015) report discusses challenges and prospects for Hong Kong and concludes that it "has all the ingredients necessary to be a global center of FinTech innovation and growth." It would be valuable to complement our research with a similar study targeting and exploring Asian countries and identifying the most prominent related subjects and, as a comparison to this study, finding the differences and similarities in FinTech development or trends. This would help researchers to adopt an even broader view of global FinTech and international information systems.

This study does not evaluate the media sources from the perspective of political or social influence, which might have some impact on the discourses observed in the study; however, we doubt that this impact would dramatically change the results. We reviewed many articles, and most of the newspapers and magazines cover general topics. Therefore, we encourage researchers to observe the current situation of FinTech, focusing more on media sources on business, technology, entrepreneurship, and finance to determine whether new topics or directions can be identified in the professional press.

Considering the observed subjects, opportunities, and issues related to FinTech, we find substantial potential for the IS community to strongly contribute to this area from the perspective of business science and information technologies. We suggest investigating the trends, directions, strengths, and weaknesses of the field from the perspective of FinTech practitioners (investors, start-ups, banks, among others). Another possible direction in which to extend this work is to analyze media sources such as blogs, podcasts, or even university courses to determine if perceptions differ from the discussed results. Moreover, we encourage researchers to use social network analysis, which was beyond the scope of this study but has the potential to provide rich results in terms of primary players, technologies, and disruptive areas of FinTech.

\section{Endnotes}

${ }^{1}$ By "media," we mean popular press. 


\section{Appendix}

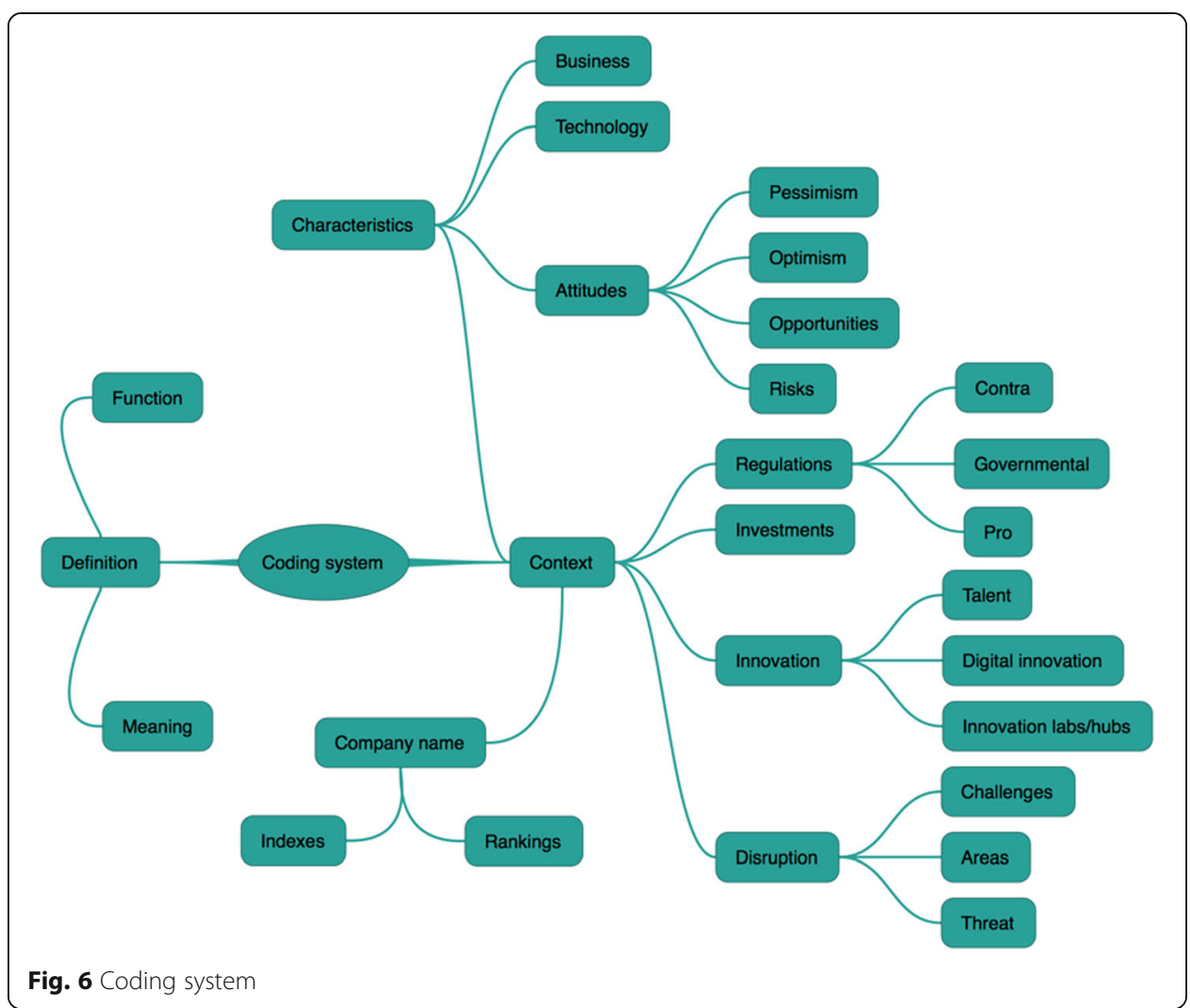

Authors' contributions

All authors contributed equally to this paper. All authors read and approved the final manuscript.

\section{Competing interests}

The authors declare that they have no competing interests.

\section{Authors' information}

Liudmila Zavolokina is a Ph.D student in Information Systems at the University of Zurich, Switzerland. Her research interests include financial and digital innovations, FinTech, blockchain technology and its applications. Mateusz Dolata is a Ph.D student in Information Systems at the University of Zurich, Switzerland. In his research on the place of IT in the modern world and in the face-to-face collaboration, he combines discourse analysis, conversation analysis, and multimodal analysis. Prof. Dr. Gerhard Schwabe is a professor in the Department of Informatics at the University of Zurich, where he leads the Information Management research group. He researches the intersection of collaborative technologies and information management. He has studied collaboration in commercial and government organizations at the granularity of dyads, small teams, large teams, organizations, communities, and social networks, frequently in collaboration with companies and public organizations.

Received: 1 November 2016 Accepted: 21 November 2016

Published online: 02 December 2016

\section{References}

Cuesta C, Ruesta M, Tuesta D, Urbiola P (2015) The digital transformation of the banking industry. BBVA Research (available at https://www.bbvaresearch.com/wp-content/uploads/2015/08/EN_Observatorio_Banca_Digital_vf3.pdf)

Cukier W, Bauer R, Middleton C (2004) Applying Habermas' Validity Claims as a Standard for Critical Discourse Analysis. In: Kaplan B, III DPT, Wastell D, Wood-Harper AT, DeGross JI (eds) Information Systems Research IFIP International Federation for Information Processing. Springer US, p 233-258 (doi: 10.1007/1-4020-8095-6_14).

Cukier W, Ngwenyama O, Bauer R, Middleton C (2009) A critical analysis of media discourse on information technology: preliminary results of a proposed method for critical discourse analysis. Inf Syst J 19(2):175-196

Dapp TF, Slomka L, Deutsche Bank AG, Hoffmann R (2014) Fintech-The digital (r) evolution in the financial sector. Deutsche Bank Research (available at https://www.dbresearch.com/PROD/DBR_INTERNET_EN-PROD/ PROD0000000000345837.pdf) 
Factiva.com (2016). Factiva.com (available at https://global.factiva.com/factivalogin/login.asp?productname=global; retrieved 8 Nov 2016).

Fichman RG, Dos Santos BL, Zheng Z (E) (2014) Digital Innovation as a Fundamental and Powerful Concept in the Information Systems Curriculum. MIS Q 38(2):329-343

Finkel JR, GrenagerT, Manning C (2005) Incorporating non-local information into information extraction systems by Gibbs sampling. In: Knight (ed.) Proc. Conf. Association for Computational Linguistics - ACLK. Association for Computational Linguistics, p 363-370.

Frame WS, White LJ (2004) Empirical studies of financial innovation: lots of talk, little action? J Econ Lit 42(1):116-144

Frame WS, White $L J$ (2014) Technological change, financial innovation, and diffusion in banking. (available at http:// ssrn.com/abstract=2380060)

International Media \& Newspapers (2015) International Media \& Newspapers (available at http://www.4imn.com/about/ index.htm\#ranking; retrieved 8 Nov 2016).

KPMG (2015) Making Hong Kong a FinTech Centre (available at https://www.kpmg.com/CN/en/IssuesAndlnsights/ ArticlesPublications/Documents/Making-HK-FinTech-Centre-201506.pdf)

Lerner J, Tufano P (2011) The consequences of financial innovation: a counterfactual research agenda. National Bureau of Economic Research

Merton RC (1995) A functional perspective of financial intermediation. Financial management, p 23-41

Miller MH (1986) Financial innovation: The last twenty years and the next. J Financ Quant Anal 21(4):459-471

Regulation of IBM (1996) (available at https://cs.stanford.edu/people/eroberts/cs181/projects/corporate-monopolies/ government_ibm.html; retrieved 10 Nov 2016).

Skan J, Dickerson J, Gagliardi L (2016) Fintech and the evolving landscape: landing points for the industry (available at http://www.fintechinnovationlablondon.co.uk/pdf/Fintech_Evolving_Landscape_2016.pdf; retrieved 29 Oct 2016).

Skan J, Dickerson J, Masood S (2015) The Future of Fintech and Banking: Digitally disrupted or reimagined? (available at http://www.fintechinnovationlablondon.co.uk/media/730274/Accenture-The-Future-of-Fintech-and-Bankingdigitallydisrupted-or-reima-.pdf)

Tufano P (2003) Financial innovation. Handbook of the Economics of Finance (1), p 307-335

Wooffitt R (2005) Conversation analysis and discourse analysis a comparative and critical introduction, London. Sage, Thousand Oaks (available at http://site.ebrary.com/lib/alltitles/docDetail.action?doclD=10256758)

Zavolokina L, Dolata M, Schwabe G (2016) FinTech - what's in a name? In: Thirty Seventh International Conference on Information Systems

Submit your manuscript to a SpringerOpen ${ }^{\circ}$ journal and benefit from:

- Convenient online submission

- Rigorous peer review

- Immediate publication on acceptance

- Open access: articles freely available online

- High visibility within the field

- Retaining the copyright to your article

Submit your next manuscript at $>$ springeropen.com 